\title{
A segunda escravidão
}

La segunda esclavitud

The second slavery

Le deuxième esclavage

Ricardo Salles [1]

\section{TOMICH, Dale. Pelo prisma da escravidão. Trabalho, Capital e Economia Mundial. São Paulo: Edusp, 2011.248 p.}

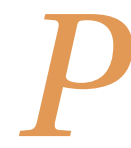
elo Prisma da Escravidão. Trabalho, Capital e Economia Mundial. Esse é o título do livro de Dale Tomich, recentemente traduzido e publicado em português pela Editora da Universidade de São Paulo. Trata-se de uma coletânea de textos do autor, professor de Sociologia e História da Universidade Estadual de Nova York, em Binghamton. Tomich é um velho conhecido e conhecedor do Brasil. ${ }^{1}$ Além disso, é envolvido com diversas pesquisas e pesquisadores brasileiros, vindo frequentemente ao país.

Pelo Prisma da Escravidão saiu em inglês, em 2004. ${ }^{2}$ O livro reúne artigos publicados entre 1987 e 1997 e está dividido em três partes. A primeira tem por título "A Escravidão na Economia Mundial" e subdividese em três capítulos. Esta resenha terá como foco os capítulos 1 e 3 dessa primeira parte. São eles que dão a perspectiva de análise que se desdobra nas duas outras partes da obra, "O Global no Local" e "Trabalho, Tempo e Resistência: Mudando os Termos da Comparação", cujos seis capítulos analisam o Caribe francês, inglês e espanhol entre finais do século XVIII e a primeira metade do século XIX.

O conceito-chave que organiza o conjunto do livro, e que dá o título do terceiro capítulo, é o de segunda escravidão. Ele é uma versão revisada do capítulo da obra coletiva Rethinking the Nineteenth Century: Movements and 
Contradictions, de $1988 .{ }^{3} \mathrm{O}$ argumento de Tomich é que a escravidão moderna não foi sempre a mesma entre os séculos XVI e XIX. Na virada do século XVIII para o XIX, um conjunto de acontecimentos e tendências históricos, principalmente o advento da Revolução Industrial na Inglaterra e a hegemonia internacional da Grã-Bretanha, levaram a reconfigurações profundas no mercado mundial. Houve um crescente desequilíbrio nos preços internacionais entre produtos industrializados e agrícolas; o incremento do consumo de determinados produtos, como o café e o açúcar, demandados pelo aumento da população de trabalhadores e da classe média nas cidades da Inglaterra e da Europa; a procura por novas matérias-primas, como o algodão. Se esse conjunto de transformações afetou determinadas áreas coloniais escravistas, implicando seu declínio, atuou sobre outras áreas escravistas quase que em sentido inverso. Em regiões como Cuba, o Sul dos Estados Unidos e o Brasil, antes em segundo plano, a escravidão "expandiu-se numa escala maciça para atender à crescente demanda mundial de algodão, café e açúcar" (p. 83). A escravidão foi refundida em uma

nova constelação de forças políticas e econômicas [...] O significado e o caráter sistêmicos da escravidão foram transformados (p. 87).

Esses centros emergentes escravistas viram-se cada vez mais integrados e impelidos pela produção industrial.

Essa 'segunda escravidão' se desenvolveu não como uma premissa histórica do capital produtivo, mas pressupondo sua existência como condição para sua reprodução (p. 87).

Estamos longe aqui da visão de uma escravidão moderna somente adstrita a um elemento subordinado do processo histórico de acumulação primitiva de capital. Uma escravidão que estaria fadada, em que pese todas as sobrevivências e resistências promovidas por grupos dominantes a ela apegados, ao desaparecimento. De tal modo que sua história ao longo do século XIX seria a história dessa morte dantesca, mas já de antemão anunciada. Antítese "das formas emergentes de Estado, sensibilidade moral e atividade econômica", a escravidão seria "o padrão negativo contra o qual as novas formas de liberdade se definiam" (p. 81). Sua abolição seria inevitável. Ainda que quase um século tenha transcorrido entre a revolução dos escravos em Saint-Domingue, em 1791, e a abolição no Brasil, em 1888, e que muitos e diferentes caminhos nacionais e regionais tenham sido trilhados nesse percurso, seu destino já estaria traçado. Para uns, pelo avanço de forças morais; para outros, pelo desenvolvimento da produção industrial e do capitalismo.

Dale Tomich nega esse modelo. Ele indica como essa segunda escravidão integrou-se ao desenvolvimento do capitalismo industrial e do mercado

${ }^{3}$ Francisco O. Ramirez (ed.), Rethinking the Nineteenth Century: Movements and Contradictions, Westport, Greenwood Press, 1988. 
mundial do século XIX sob a hegemonia britânica. E, por isso, mesmo que contraditoriamente, desenvolveu-se com ele, não a despeito dele. Neste ponto, ao traçar o objetivo do capítulo como sendo o de chamar a atenção para o caráter diverso da escravidão no século XIX, dada sua integração com o desenvolvimento do capitalismo, o autor adverte que não se propõe "explicar as causas da emancipação dos escravos, que permanecem diversas e conjunturais" (p. 82). Trata-se de chamar a atenção para a "formação e reformulação das relações escravistas dentro dos processos históricos da economia capitalista mundial" (p. 82). Assim, se

a escravidão foi ao fim e ao cabo abolida em todos os quadrantes do hemisfério, o 'século antiescravista' foi, não obstante, o apogeu de seu desenvolvimento (p. 82).

No primeiro capítulo da primeira parte do livro, "Capitalismo, Escravidão e Economia Mundial”, está exposta a visão teórica, que embasa o conceito de segunda escravidão, se complementa e se aprofunda. Cronologicamente, o capítulo, assim como o segundo, que não será tratado aqui, foi escrito em 1993, posteriormente ao terceiro capítulo. ${ }^{4}$ Entretanto, do ponto de vista teórico, da exposição e da unidade do livro, corretamente, ele aparece antes. O fato não é de menor importância e ressalta um ponto decisivo na obra, a centralidade do que Tomich chama de história teórica.

\section{Estamos longe aqui da visão de uma escravidão moderna somente adstrita a um elemento subordinado do processo histórico de acumulação primitiva de capital}

Para abrir sua argumentação, ele aponta as debilidades de três grandes interpretações sobre a escravidão moderna: a da Nova História Econômica, presente nas obras de John H. Conrad e John R. Meyer e de Robert W. Fogel e Stanley L. Engerman; a marxista, de Eugene Genovese, e a do Moderno Sistema Mundo, de Immanuel Wallerstein. ${ }^{5}$ Resumida e esquematicamente, a Nova História Econômica presumiria a validade universal das categorias econômicas, aplicáveis tanto à economia capitalista quanto à economia escravista, deixando sem respostas as questões pertinentes à interpretação histórica e à formação das relações sociais. Já Genovese veria escravidão e capitalismo

${ }^{4}$ Dale Tomich, "World Market and American Slavery, Problems of Historical Method", em Manuel Ceda (ed.), Els espais del mercat, Valência, Diputació de Valencia, 1933. pp. 213-240.

${ }^{5}$ John H. Conrad \& John R. Meyer, The Economics of Slavery and Other Studies in Economic History, Chicago, Aldine, 1964; Robert W. Fogel \& Stanley L. Engerman, Time on the Cross. The Economics of American Slavery, Boston, Little Brown and Company, 1974, 2 v.; Eugene D. Genovese, The Political Economy of Slavery, Nova York, Random House, 1967; Immanuel Wallerstein, The Capitalist World-Economy, Nova York, Cambridge University Press, 1979. 
como sistemas incompatíveis, este mais moderno e aquele mais atrasado, envolvendo momentos diferentes do processo evolutivo histórico. Finalmente, para Wallerstein, o Moderno Sistema-Mundo, compreendendo relações de trabalho tanto assalariadas quanto coercitivas - dentre elas, a escravidão - , se constituiria em uma só estrutura histórica empírica, com múltiplas formas de trabalho, entretanto perdendo de vista as diferenças fundamentais entre as distintas relações sociais de produção.

Ao fim dessa digressão crítica sobre esses autores, Tomich propõe uma distinção fundamental entre teoria histórica, "preocupada em formular as categorias teóricas apropriadas para a compreensão de um objeto de investigação historicamente distinto", e história teórica, "preocupada com o uso de tais categorias para reconstruir os processos de desenvolvimento histórico" (p. 37).

No primeiro caso, trata-se do que Marx fez em O Capital: construir um objeto teórico, o capital, assinalando sua especificidade "como uma forma histórica particular de relação social de produção e o trabalho como seu conteúdo" (p. 39, grifo no original). Apesar de dizer respeito a uma época particular da história e de fazer diversas referências a lugares - como a Inglaterra da Revolução Industrial - e a processos históricos concretos, como no caso de sua descrição do processo de acumulação original de capital, Marx concatena suas categorias logicamente. Essa tensão inerente a seu método, como crítica das categorias universais da economia política, entre sua proposta de assinalar a historicidade e o caráter relacional dessas categorias - capital e trabalho - e a exposição lógica de seus próprios conceitos, está na raiz dos equívocos das intepretações sobre a escravidão, criticadas por Tomich. Todas, de uma maneira ou de outra, tratariam capitalismo e escravidão como entidades abstratas e separadas, dotadas de atributos essenciais.

A implicação dessas concepções, pode-se dizer, é que a escravidão acaba ficando "fora do lugar". Resumida a uma contingência histórica da fase de acumulação original de capital, ela é subsumida inteiramente à lógica do capitalismo, perdendo sua especificidade e sua história (como no caso das perspectivas da Nova História Econômica e do Moderno Sistema-Mundo). $\mathrm{Ou}$, então, ela ganha contornos de um sistema, que teve uma função na fase de acumulação original, mas que se tornou crescentemente anacrônico e incompatível com o próprio capitalismo (marxismo).

Nesse ponto, o conceito de segunda escravidão, ao assinalar o recrudescimento sem precedentes das formas escravistas, exatamente no momento em que o mercado mundial se expande sob a hegemonia da Grã-Bretanha, onde se desenvolve o cerne da Revolução Industrial, mostra toda sua força. A escravidão não é mais vista como uma entidade abstrata, sempre igual a si mesma, e, sem se confundir em sua configuração com o capitalismo, integra com ele o mesmo mundo, ainda que de forma complexa e contraditória. Capitalismo e escravidão, do ponto de vista de uma história teórica, passam a ser encarados como "formas específicas de produção ou troca social", que não são entendidas 
como unidades autônomas com sua própria história, mas sim como sendo formadas por meio de sua relação com a totalidade político-econômica mais ampla (p. 50).

Totalidade essa que afetava diretamente a vida de senhores, escravos e de suas sociedades de uma maneira geral. Essa totalidade, da qual a segunda escravidão foi parte integrante e ativa fundamental, e não apenas um apêndice ou sobrevivência colonial ou do Antigo Regime, foi, por sua vez, afetada pelas ações e lutas de senhores, escravos e demais atores sociais, políticos e culturais das sociedades escravistas americanas. Uma e outra coisa não podem ser ignoradas pelo historiador, sob a pena de se fazer uma história capenga, reproduzindo ou deixando intocados estereótipos e tradições sobre noções como liberdade, trabalho livre, liberalismo, capitalismo e, é claro, escravidão.

Se a perspectiva proposta é para valer, é preciso repensar o significado das lutas escravas no contexto da segunda escravidão, quais eram suas condicionantes e quais foram suas consequências. Uma tal diferença entre situações históricas, como aquela experimentada entre a "primeira" e a segunda escravidão, sem falar das diferenças mais específicas de cada contexto e conjuntura particulares, não pode ser completamente compreendida sem remissão ao quadro mais global da economia-mundo capitalista e da segunda escravidão.

\section{A escravidão não é mais vista como uma entidade abstrata, sempre igual a si mesma}

Uma palavra final sobre a elaboração e a recepção do conceito de segunda escravidão, que vem sendo crescentemente discutido por vários historiadores, no Brasil e fora daqui. ${ }^{6}$ Como vimos, ele foi elaborado originalmente em 1988, tendo reaparecido na primeira edição do livro, em inglês, em 2004. Essa reaparição não foi apenas editorial. Em 1988, no auge da voga da micro-história, da virada linguística, do individualismo metodológico e de tudo mais que, no apogeu do neoliberalismo, prometia sepultar o marxismo e outras visões

\footnotetext{
${ }^{6}$ Cf. Christopher Schmidt-Nowara, Empire and Antislavery: Spain, Cuba and Puerto Rico, 1833 - 1874, Pittsburgh, University of Pittsburgh Press, 1999; Rafael Marquese, Feitores do corpo, missionários da mente. Senhores, letrados e o controle dos escravos nas Américas, 1660-1860, São Paulo, Companhia das Letras, 2004; Ricardo Salles, E o Vale era o escravo - Vassouras, século XIX. Senhores e escravos no Coração do Império, Rio de Janeiro, Civilização Brasileira, 2008; Michael Zeuske, "Comparing or interlinking? Economic comparisons of early nineteenth-century slave systems in the Americas in historical perspective", in Enrico dal Lago \& Constantina Katsari (eds.), Slave Systems. Ancient and Modern, Cambridge, Cambridge University Press, 2008, p. 148-183; José A. Piqueras (ed.), Trabajo Libre y Coactivo en Sociedades de Plantación, Madri, Siglo XXI, 2009; Anthony Kaye, "The Second Slavery: Modernity in the Nineteenth-Century South and the Atlantic World", Jornal of Southern History, vol. 73, n. 3, August 2009, p. 627-50; Rafael Marquese, Márcia Berbel e Tâmis Parron, Escravidão e política. Brasil e Cuba, c.1790-1850, São Paulo, Hucitec, 2010; Tâmis Parron, A política da escravidão no Império do Brasil, 1826-1865, Rio de Janeiro, Civilização Brasileira, 2011; Robin Blackburn, The American Crucible. Slavery, Emancipation and Human Rights, Londres, Verso, 2011; Enrico Dal Lago, American Slavery, Atlantic Slavery, and Beyond. The U.S. "Peculiar Institution" in International Perspective, Boulder, Paradigm Publishers, 2012.
} 
totalizantes da história, o texto de Tomich passou despercebido. Parece que agora as coisas se dão de forma diferente. A começar pelo neoliberalismo, que, além de se ver reduzido a uma doutrina fomentadora das altas finanças, mergulhou o mundo em uma crise sem precedentes nos últimos 70 anos. No campo da historiografia, as descrições densas do particular, do cotidiano e do miúdo, precedidas de rápidas pinceladas de contexto, acrescidas de duas ou três generalizações superficiais que eludem a necessidade da análise mais abrangente, aprofundada e concreta dos objetos históricos, cedem espaço. Se elas ajudaram a superar a antiga abordagem dos sistemas, de matriz sociológica, abstrata e lógica, hoje, já não são suficientes. ${ }^{7}$ Trata-se, agora, de buscar análises que se voltem para as conexões, os nexos e as contradições que compõem esses objetos enquanto totalidades estruturadas, produzidas pelas ações humanas ao mesmo tempo em que as condicionam. Isso é o que Pelo Prisma da Escravidão busca, indicando caminhos para que seja feito e bem feito. 